\title{
Clinical Utility of Central and Peripheral Airway Nitric Oxide in Aging Patients with Stable and Acute Exacerbated Chronic Obstructive Pulmonary Disease
}

This article was published in the following Dove Press journal: International Journal of General Medicine

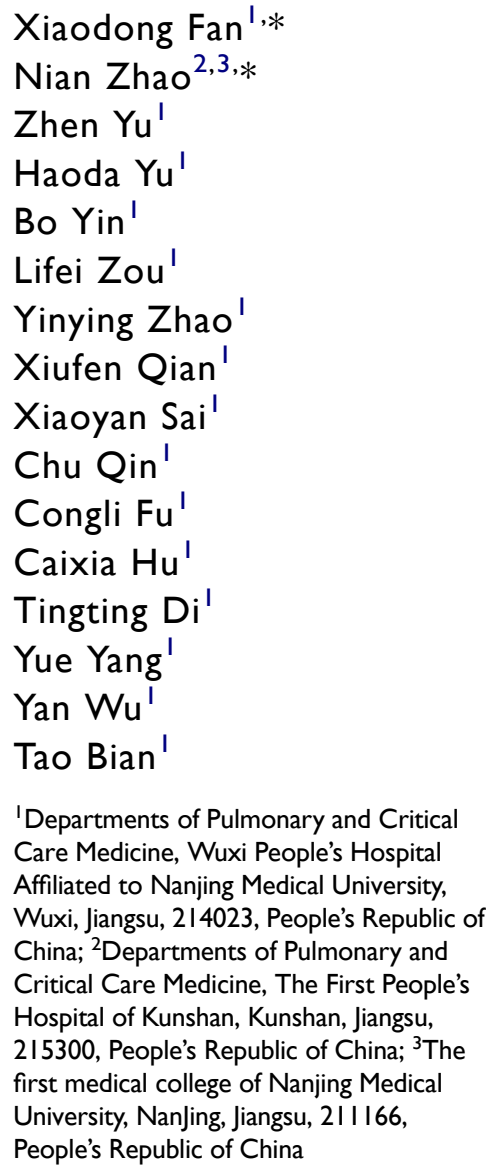

*These authors contributed equally to this work

Correspondence: Yan Wu; Tao Bian Department of Pulmonary and Critical Care Medicine, Wuxi People's Hospital Affiliated to Nanjing Medical University, Wuxi, Jiangsu, 2 I 4023, People's Republic of China

Email wuyanyangting@।63.com;

biantaophd@I26.com
Purpose: Exhaled nitric oxide has been used as a marker of airway inflammation. The NO concentration in the central and peripheral airway/alveolar can be measured by a slow and fast exhalation flow rate to evaluate inflammation in different divisions within the respiratory tract. We hypothesized that $\mathrm{FeNO}_{200}$ (exhaled $\mathrm{NO}$ at a flow rate of $200 \mathrm{~mL} / \mathrm{s}$ ) could be used as an evaluation tool for peripheral airway/alveolar inflammation and corticosteroid therapy in chronic obstructive pulmonary disease (COPD) patients.

Methods: We recruited 171 subjects into the study: 73 healthy controls, 59 stable COPD patients, and 39 acute exacerbations of COPD (AECOPD) patients. Exhaled nitric oxide $\left(\mathrm{FeNO}_{50}\right.$ (exhaled $\mathrm{NO}$ at a flow rate of $\left.50 \mathrm{~mL} / \mathrm{s}\right)$ ), $\mathrm{FeNO}_{200}$ and $\mathrm{CaNO}$ (peripheral concentration of $\mathrm{NO} /$ alveolar $\mathrm{NO}$ ) and clinical variables including pulmonary function, COPD Assessment Test (CAT), C-reactive protein concentration (CRP) and circulating eosinophil count were measured among the recruited participants. $\mathrm{FeNO}_{50}, \mathrm{FeNO}_{200}$ and $\mathrm{CaNO}$ were repeatedly evaluated in 39 AECOPD patients after corticosteroid treatment.

Results: $\mathrm{FeNO}_{200}$ was significantly higher in stable COPD and AECOPD patients than in healthy controls. Nevertheless, CaNO could not differentiate COPD from healthy controls. No correlation was found between circulating eosinophil counts or FEV1 and exhaled nitric oxide $\left(\mathrm{FeNO}_{50}, \mathrm{FeNO}_{200}, \mathrm{CaNO}\right)$ in COPD patients. For AECOPD patients, $64 \%$ of patients had eosinophil counts $>100$ cells $/ \mu \mathrm{L} ; 59 \%$ of patients had $\mathrm{FeNO}_{200}>10 \mathrm{ppb}$; only $31 \%$ of patients had $\mathrm{FeNO}_{50}>25 \mathrm{ppb}$. Among AECOPD patients, the high $\mathrm{FeNO}_{50}$ and $\mathrm{FeNO}_{200}$ groups' levels were significantly lower than their baseline levels, and significant improvements in CAT were seen in the two groups after corticosteroid treatment. These implied a good corticosteroid response in AECOPD patients with $\mathrm{FeNO}_{200}>10 \mathrm{ppb}$.

Conclusion: $\mathrm{FeNO}_{200}$ is a straightforward and feasible method to evaluate the peripheral NO concentration in COPD. FeNO200 can be a type 2 inflammation biomarker and a useful tool for predicting corticosteroid therapy in COPD.

Keywords: exhaled nitric oxide, chronic obstruction pulmonary disease, corticosteroid, biomarker

\section{Introduction}

Chronic obstructive pulmonary disease (COPD) is a complex polyclinic lung disease characterized by an abnormal inflammatory and a progressive condition with declining lung function. ${ }^{1}$ Although airway inflammation in COPD is generally considered to be caused by type 1 immune response, type 2 airway inflammation 
can also occur in some COPD patients during stable or exacerbation state. ${ }^{2}$ Some studies have found that some COPD patients have gene expression of type 2 inflammation in the airway, and these patients have a good response to corticosteroid. ${ }^{3}$ In recent years, there have been a large number of studies on the role of type 2 biomarkers in COPD, including eosinophils, IgE and $\mathrm{FeNO}_{50}{ }^{4}$ Nitric oxide (NO) is biosynthesized from L-arginine and oxygen by the enzyme NO synthase (NOS) endogenously, fractional concentration of exhaled nitric oxide at a flow rate of $50 \mathrm{~mL} / \mathrm{s}\left(\mathrm{FeNO}_{50}\right)$ is a known marker of airway inflammation. As a noninvasive, convenient and highly reproducible method for assessing airway inflammation, FeNO measurement has been used to evaluate type 2 inflammation of asthma and guide anti-inflammatory treatment. ${ }^{5,6}$ However, the role of $\mathrm{FeNO}_{50}$ in COPD remains controversial. $^{7-10}$

According to the latest technical standard published by the European Respiratory Society (ERS) in 2017, $\mathrm{FeNO}_{50}$ (usually abbreviated as FeNO, representing the exhaled NO value at the flow rate of $50 \mathrm{~mL} / \mathrm{s}$ ) mainly reflects large airway inflammation from bronchi to respiratory bronchioles, but cannot reflect small airway inflammation. ${ }^{11}$ COPD is a respiratory disease characterized by chronic inflammation of the small airway. As a marker of peripheral/small airway inflammation, more and more studies began to pay attention to the clinical value of CaNO (concentration of alveolar NO) in COPD patients. Several studies reported that $\mathrm{CaNO}$ was increased in COPD patients and was correlated with a single nitrogen washout curve (dN2) and diffusion capacity for carbon monoxide (DLCO) ${ }^{12-17}$ Nonetheless, some researchers found that there was no difference in CaNO between COPD patients and healthy population. ${ }^{18}$ In addition, whether CaNO could guide the treatment of corticosteroid in COPD patients needs further study.

The estimation of $\mathrm{CaNO}$ requires three exhalations at three different flow rates that follow the conventional linear regression model. The procedure is complex, especially for AECOPD patients, it is challenging to complete. ${ }^{16}$ Therefore, it is necessary to have a simpler and more convenient index than CaNO, but it can also reflect peripheral/small airway inflammation. In 2014, Peter J Barnes found that $\mathrm{FeNO}_{200}$ (fractional concentration of exhaled nitric oxide at a flow rate of $200 \mathrm{~mL} / \mathrm{s}$ ) is proportional to $\mathrm{CaNO}$. By measuring the exhaled $\mathrm{NO}$ at the flow rates of $50 \mathrm{~mL} / \mathrm{s}$ and $200 \mathrm{~mL} / \mathrm{s}$, the inflammation of central and peripheral airways can be distinguished. ${ }^{19}$ Therefore, $\mathrm{FeNO}_{200}$ (fractional concentration of exhaled $\mathrm{NO}$ at a flow rate of $200 \mathrm{~mL} / \mathrm{s}$ ) was used as it maximizes the alveolar fraction of eNO in hereditary hemorrhagic telangiectasia, hepatopulmonary syndrome, and liver cirrhosis. ${ }^{20-22}$ However, the role of $\mathrm{FeNO}_{200}$ in patients with COPD has not been studied.

Our prospective study measured pulmonary function parameters and exhaled nitric oxide $\left(\mathrm{FeNO}_{50}, \mathrm{FeNO}_{200}\right.$, and $\mathrm{CaNO}$ ) in COPD patients with different stages and controls. For AECOPD patients, we compared these parameters before and after corticosteroid treatment. The purpose of this study was to evaluate a change in peripheral small airway/alveolar sites of $\mathrm{NO}$ detected by $\mathrm{FeNO}_{200}$ and $\mathrm{CaNO}$ in COPD. Besides, whether $\mathrm{FeNO}_{200}$ or $\mathrm{CaNO}$ could be used as an evaluation tool for corticosteroids therapy in AECOPD patients was further explored.

\section{Materials and Methods \\ Study Subjects}

Stable COPD patients and AECOPD patients were diagnosed based on the Global Initiative for Chronic Obstructive Lung Disease (GOLD) 2017 guidelines. Healthy subjects (HS) with normal lung function as controls were included in the study. All participants were restricted to adults 60 years and older. The physician prescribed the therapy of AECOPD. Patients enrolled at the Department of Respiratory Medicine at the Wuxi People's Hospital from November 2017 to December 2019.

For all participants with a history of asthma or other respiratory diseases were excluded from the study. The main exclusion criteria were treated with systemic corticosteroids or antibiotics 4 weeks before admission. The hospital Ethics Committee approved the study. We fully abide by the guidelines in the Helsinki declaration and written informed consent was obtained from all participants enrolled in the study.

\section{Study Design}

Lung function, exhaled nitric oxide, the white blood cell count (WBC), and blood C-reactive protein (CRP) concentration were measured among the controls and COPD patients. For AECOPD patients, methylprednisolone $40 \mathrm{mg} /$ day, intravenous administration for 1 week was given. Moreover, before discharged from the hospital, lung function and exhaled nitric oxide would be measured again in AECOPD patients. 


\section{Exhaled NO Measurement}

Exhaled NO was measured using the Nano Coulomb Breath Analyzer (Sunvou-CA2122, Wuxi, China), in line with the American Thoracic Society/European Respiratory Society (ATS/ERS) recommendations. ${ }^{23}$ One hour before the test, eating, smoking, drinking, strenuous exercise or pulmonary function test were prohibited.

Ten healthy controls, ten stable COPD patients, and ten AECOPD patients participated in the preliminary clinical trial. They were required to exhale via a mouthpiece at multiple flow rates: 100, 200, 350mL/s. At each flow rate, the mean value was calculated. FeNO50 was measured at the single flow rate of $50 \mathrm{~mL} / \mathrm{s}$. CaNO was estimated with a mathematical approach based on a two-compartment linear model published by Tsoukias et al. ${ }^{24}$ However, the success rate of measurement at a flow rate of $350 \mathrm{~mL} / \mathrm{s}$ was only $60 \%$ for AECOPD patients (Table 1).

A simplified estimation method of alveolar nitric oxide was developed to improve the success rate of measurement. Subjects were informed about inhaling NO-free air and exhaling via a mouthpiece at two constant flow rates: 50, $200 \mathrm{~mL} / \mathrm{s}$. $\mathrm{FeNO}_{50}$ and $\mathrm{FeNO}_{200}$ were recorded. CaNO was calculated based on the linear model published by ERS:

$\mathrm{FeNO}=\mathrm{CaNO}+\mathrm{JawNO} / \mathrm{VE}$

FeNO (fractional concentration of exhaled NO) is recorded in $\mathrm{ppb}(1 \mathrm{ppb}=1 \times 10-9 \mathrm{~mol} / \mathrm{L})$. The exhalation flow rate is given as a subscript in $\mathrm{mL} / \mathrm{s}$. A flow rate of $50 \mathrm{~mL} / \mathrm{s}$ is written $\mathrm{FeNO}_{50}$ and a low rate of $200 \mathrm{~mL} / \mathrm{s}$ is written $\mathrm{FeNO}_{200}$. FeNO is a flow rate dependent index. The smaller the flow rate is, the higher the value is, the better it can reflect NO in a large airway; the higher the flow rate, the smaller the value, the better it can reflect $\mathrm{NO}$ in a small airway. JawNO, the total flux of $\mathrm{NO}$ in the conducting airway compartment $(\mathrm{nl} / \mathrm{s})$, is not affected by the flow rate and only reflects the inflammation of the central/large airway. CaNO, the concentration of alveolar NO, is not affected by the flow rate and only reflects the inflammation of peripheral/small airway.

Table I The Success Rate of Exhaled Nitric Oxide Measurement at Different Expiratory Flow Rates

\begin{tabular}{|l|l|l|l|l|}
\hline Exhalation Flow Rates, $\mathbf{~ m L} / \mathbf{s}$ & $\mathbf{5 0}$ & $\mathbf{1 0 0}$ & $\mathbf{2 0 0}$ & $\mathbf{3 5 0}$ \\
\hline Control & $100 \%$ & $100 \%$ & $100 \%$ & $90 \%$ \\
Stable COPD & $100 \%$ & $100 \%$ & $90 \%$ & $70 \%$ \\
AECOPD & $100 \%$ & $100 \%$ & $90 \%$ & $\mathbf{6 0 \%}$ \\
\hline
\end{tabular}

\section{Statistical Analysis}

SPSS software vsrsion22.0 was used to process data. All continuous variables were checked for normal distribution by Kolmogorov-Smirnov normality test. Normally distributed variables are expressed as mean \pm standard deviation, and skewed variables are expressed as the median (interquartile range, IQR). The significance of the difference between the two groups was assessed with a two-tailed Manne-Whitney test ( $t$-test). The differences between multiple groups were evaluated with the nonparametric Kruskal-Wallis test (ANOVA) with Dunn post-test. The chi-square test was used to compare categorical variables between the two groups. Statistical significance was considered to exist when $\mathrm{P}<0.05$.

\section{Results \\ Subject Characteristics}

A total of 98 COPD patients (59 stable COPD patients, 39 AECOPD patients) and 73 healthy controls were enrolled in this study. The characteristics of the study patients are shown in Table 2. There were no statistical differences in terms of age, blood eosinophil percentage, and eosinophil counts. Elevated CRP concentration was seen in COPD patients. Pulmonary function parameters were significantly higher in healthy controls than in COPD patients. In the stable COPD and AECOPD patients, lung function parameters and maintenance therapy were similar. There was no significant difference in the distribution of disease severity between the COPD and AECOPD patients.

\section{Increased Exhaled Nitric Oxide in Different Stages of COPD}

$\mathrm{FeNO}_{200}$ elevated in patients with stable COPD [median: $11.0 \mathrm{ppb}$, IQR: $(9.0,15.0) \mathrm{ppb} ; \mathrm{P}<0.05]$ and AECOPD patients [meidan: $11.0 \mathrm{ppb}$, IQR: (10.0, 14.0) ppb; $\mathrm{P}<0.05$ ] compared with healthy controls [median: 9.0 ppb, IQR: $(6.0,11.0) \mathrm{ppb}$. $\mathrm{FeNO}_{50}$ increased in patients with stable COPD [median: 22.0 ppb, IQR: (17.0, 30.0) ppb; $\mathrm{P}<0.05$ ] and exacerbated COPD patients [median: 21.0 ppb, IQR: $(18.0,28.0) \mathrm{ppb}$; $<<0.05$ ] compared with healthy controls [median: $20.0 \mathrm{ppb}, \mathrm{IQR}:(15.0,25.0)$ $\mathrm{ppb}$. However, there was no significant difference in $\mathrm{FeNO}_{50}$ and $\mathrm{FeNO}_{200}$ between stable and exacerbated COPD patients. CaNO demonstrated no significant difference among control subjects [median: $4.4 \mathrm{ppb}$, IQR: (1.5, 6.7) $\mathrm{ppb}$ ], stable [median: $5.9 \mathrm{ppb}, \mathrm{IQR}:(3.5,8.2) \mathrm{ppb}$ and exacerbated COPD patients [median: $5.4 \mathrm{ppb}, \mathrm{IQR}$ : $(2.6,8.5) \mathrm{ppb}$ (Figure 1). 
Table 2 The Clinical Characteristics of the Patients and Control

\begin{tabular}{|c|c|c|c|c|c|}
\hline & Control & Stable COPD & AECOPD & P-value & Paired Comparison Results \\
\hline \multicolumn{6}{|l|}{ Demographics } \\
\hline Numbers & 73 & 59 & 39 & & \\
\hline Age (years) & $67 \pm 6$ & $69 \pm 7$ & $68 \pm 7$ & 0.055 & 一 \\
\hline Gender $(\%$ male $) *$ & $54(74 \%)$ & $57(97 \%)$ & $37(95 \%)$ & 0.000 & Control, Stable COPD>AECOPD \\
\hline Current smoker* & $23(32 \%)$ & $34(56 \%)$ & $18(45 \%)$ & 0.018 & Stable COPD>AECOPD>Control \\
\hline \multicolumn{6}{|l|}{ Comorbiditis } \\
\hline Hypertension & 4 & 17 & 15 & 一 & \\
\hline Diabetes & 3 & 4 & 2 & 一 & \\
\hline \multicolumn{6}{|l|}{ Blood test } \\
\hline Eosinophil count/ul & $0.10(0.07,0.17)$ & $0.14(0.05,0.27)$ & $0.15(0.04,0.21)$ & 0.571 & 一 \\
\hline Eosinophil count $\geq 100$ cells/ul,\% & - & $47 \%$ & $64 \%$ & & \\
\hline CRP, mg/l & $0.8(0.5,2.1)$ & $2.8(0.5,9.0)$ & $4.0(1.0,10.9)$ & 0.002 & AECOOD>Stable COPD>Contro \\
\hline \multicolumn{6}{|l|}{ Pulmonary function } \\
\hline VC MAX & $2.98 \pm 0.71$ & $2.68 \pm 0.67$ & $2.5 I \pm 0.78$ & 0.000 & Control>Stable COPD, AECOPD \\
\hline FEVI/FVC & $80.74(72.40,94.17)$ & $50.11 \pm 9.43$ & $48.9 \pm 11.5$ & 0.000 & Control>Stable COPD, AECOPD \\
\hline FEVI\% pred & $91.79 \pm 18.80$ & $46.81 \pm 16.00$ & $39.6(30.1,54.1)$ & 0.000 & Control>Stable COPD, AECOPD \\
\hline PEF & $6.48 \pm 1.98$ & $3.3(1.62,7.92)$ & $2.9(2.0,3.9)$ & 0.000 & Control>Stable COPD, AECOPD \\
\hline FEF25 & $6.27 \pm 2.04$ & I.2I $(0.55,3.82)$ & $0.83(0.58,1.78)$ & 0.000 & Control>Stable COPD, AECOPD \\
\hline FEF50 & $5.03 \pm 2.13$ & $0.61(0.26,1.36)$ & $0.42(0.28,0.76)$ & 0.000 & Control>Stable COPD, AECOPD \\
\hline FEF75 & $2.64 \pm 1.48$ & $0.20(0.10,0.44)$ & $0.19(0.15,0.29)$ & 0.000 & Control>Stable COPD, AECOPD \\
\hline \multicolumn{6}{|l|}{ Treatment } \\
\hline ICS, N & NA & 43 & 39 & 0.241 & \\
\hline ICS dose,ug BUD & NA & $640(640-800)$ & $640(640-800)$ & 0.930 & \\
\hline LABA, N & NA & 46 & 37 & 1.000 & \\
\hline LAMA, N & NA & 51 & 32 & 0.420 & \\
\hline Oral theophylline, $\mathrm{N}$ & NA & 12 & 13 & 0.210 & \\
\hline
\end{tabular}

Notes: Data are presented as mean \pm standard deviation, median (interquartile range), or number of subjects (proportion); ${ }^{*}$ Mantel-Haenszel chi-square test for Gender and Current smokers; Kruskal-Wallis test for all other variables; Comparisons made between Control, Stable COPD and AECOPD categories .

Abbreviations: CRP, blood C-reactive protein; VT, tidal volume; VC MAX, VC, vital capacity; FEVI, forced expiratory volume in I second; FVC, forced vital capacity. PEF, peak expiratory flow; FEF25, forced expiratory flow when $25 \%$ of vital capacity is exhaled; ICS, inhaled corticosteroid; LABA, long-acting $\beta 2$-agonist; LAMA, long-acting muscarinic antagonist.

There was a positive correlation between $\mathrm{FeNO}_{50}$ and CRP $(r=0.384, p<0.05)$ in stable COPD patients. $\mathrm{FeNO}_{200}$ was associated with CRP $(r=0.335, \mathrm{p}<0.05)$ as well. CaNO did not correlate with CRP ( $>00.05)$. Forty-seven percent stable COPD patients and 64\% AECOPD patients with blood eosinophil counts $\geq 100$ cells/ul. No correlation was found between exhaled nitric oxide $\left(\mathrm{FeNO}_{50}, \mathrm{FeNO}_{200}\right.$, $\mathrm{CaNO})$ and eosinophils $(\mathrm{P}>0.05)$. In AECOPD patients, there was no correlation between exhaled nitric oxide and eosinophils and CRP ( $>0.05)$.

\section{Effect of Corticosteroids on Exhaled Nitric Oxide in AECOPD Patients}

Exhaled NO was repeatedly measured in 39 patients with AECOPD before discharge from the hospital following adequate corticosteroid treatment. During hospitalization, all patients were treated continuously with systemic corticosteroids. There were significant improvements in $\mathrm{FeNO}_{50}$, lung function (FEV 1\%, PEF, FEF25, FEF50, FEF75) (Table 3).

\section{$\mathrm{FeNO}_{200}>10 \mathrm{ppb}$ Predicted a Good Corticosteroid Response in AECOPD}

We grouped all patients according to the cut-off point of $\mathrm{FeNO}_{50}, \mathrm{FeNO}_{200}$ and $\mathrm{CaNO}$. According to the clinical guideline published by ATS in 2011, $\mathrm{FeNO}_{50}$ values greater than $25 \mathrm{ppb}$ indicate eosinophilic inflammation and the likelihood of corticosteroid responsiveness. No guidelines have published cut-off points for $\mathrm{FeNO}_{200}$ and CaNO. Based on the literature, the normal values of $\mathrm{FeNO}_{200}$ and $\mathrm{CaNO}$ in healthy people do not exceed 7.4 ppb and $4.7 \mathrm{ppb}$, so we use $10 \mathrm{ppb}$ and $5 \mathrm{ppb}$ as the cut-off point. $^{20,25,26}$ 

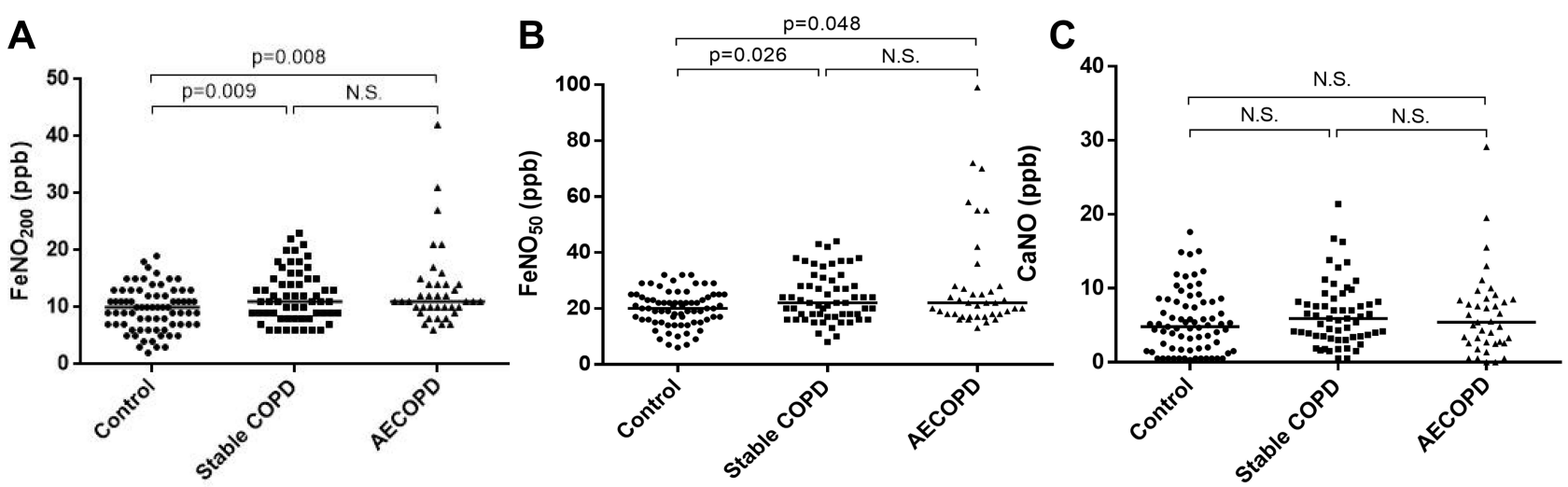

Figure I Exhaled nitric oxide in healthy controls, stable and exacerbated COPD patients. FeNO $\mathrm{N}_{50}$ increased in stable and exacerbated COPD patients (A). FeNO 200 increased in stable and exacerbated COPD patients (B). There was no significant difference of CaNO in healthy controls, stable and exacerbated COPD patients (C).

There were 11 patients with initial $\mathrm{FeNO}_{50}>25$ ppb, $\mathrm{FeNO}_{50}$ decreased significantly from $51.7 \pm 22.7$ $\mathrm{ppb}$ to $30.3 \pm 9.0 \mathrm{ppb}(\mathrm{p}<0.05)$ after a week of corticosteroid treatment (Figure 2A). For 28 patients with initial $\mathrm{FeNO}_{50} \leq 25 \mathrm{ppb}, \mathrm{FeNO}_{50}$ did not change significantly $(19.0 \pm 3.2$ vs $20.0 \pm 9.3 \quad \mathrm{ppb} ; \quad \mathrm{p}=0.764)$ (Figure 2B). There were 23 patients with initial $\mathrm{FeNO}_{200}>10 \mathrm{ppb}, \mathrm{FeNO}_{200}$ decreased from 16.1 \pm 7.8 to $12.2 \pm 5.2$ after treatment $(\mathrm{p}<0.05)$ (Figure $2 \mathrm{C}$ ). And for 16 patients with initial $\mathrm{FeNO}_{200} \leq 10 \mathrm{ppb}$, there was no significant change after treatment $(8.7 \pm 1.4$ vs $10.3 \pm 4.3 \mathrm{ppb} ; \mathrm{p}=0.112$ ) (Figure 2D). There were 18 patients with initial $\mathrm{CaNO}>5 \mathrm{ppb}$ and 21 patients $\leq 5$ $\mathrm{ppb}$, and no significant change was found in neither group $(10.3 \pm 5.9$ vs $7.4 \pm 5.0 \mathrm{ppb}, \mathrm{p}=0.181 ; 2.6 \pm 1.5$ vs $4.5 \pm 5.7 \mathrm{ppb}, \mathrm{p}=0.148$; Figure $2 \mathrm{E}$ and $\mathrm{F}$ ).

The patients in the high $\mathrm{FeNO}_{50}$ group $\left(\mathrm{FeNO}_{50}>25\right.$ $\mathrm{ppb})$ had greater improvement in $\mathrm{FeNO}_{50}$ and $\mathrm{CAT}$ than the low $\mathrm{FeNO}_{50}$ group $\left(\mathrm{FeNO}_{50} \leq 25 \mathrm{ppb}\right)$ (Table 4).
Similar results were found between the high $\mathrm{FeNO}_{200}$ group $\left(\mathrm{FeNO}_{200}>10 \mathrm{ppb}\right)$ and low $\mathrm{FeNO}_{200}$ group $\left(\mathrm{FeNO}_{200} \leq 10 \mathrm{ppb}\right)$ (Table 5). No improvement was observed in both high and low CaNO groups (Table 6).

\section{No Relationship Between COPD Severity and Exhaled Nitric Oxide}

According to the GOLD criteria, four patients were categorized as GOLD stage1 (FEV1\% pred $\geq 80 \%$ ), 32 as GOLD stage $2(80 \%>$ FEV $1 \%$ pred $\geq 50 \%), 41$ as GOLD stage $3(50 \%>$ FEV $1 \%$ pred $\geq 30 \%$ ) and 21 as stage 4 (FEV1\% pred $<30 \%$ ).

The increase of CaNO from GOLD1-2 to GOLD3, GOLD 3 to GOLD 4 was insignificant, but there was a significant increase from GOLD 1-2 to GOLD 4 (Figure 3C). And no difference was found between different GOLD stages in $\mathrm{FeNO}_{50}$ and $\mathrm{FeNO}_{200}$ (Figure 3A and B).

No correlations were found between $\mathrm{FeNO}_{50}$, $\mathrm{FeNO}_{200}, \mathrm{CaNO}$ and FEV1 ( $\left.>0.05\right)$.

Table 3 Changes in Exhaled NO and Pulmonary Function in AECOPD Patients After Treatment

\begin{tabular}{|l|l|l|l|l|}
\hline & Before & After & Difference (After-Before) & $\boldsymbol{p}$ value \\
\hline $\mathrm{FeNO}_{50}$ & $22.0(18.0,28.0)$ & $22.7 \pm 9.5$ & $-3.0(-10.0,3.0)$ & 0.037 \\
$\mathrm{FeNO}_{200}$ & $11.0(10.0,14.0)$ & $10.0(8.0,14.0)$ & $0.0(-5.0,2.0)$ & 0.118 \\
$\mathrm{CaNO}$ & $5.4(2.7,8.5)$ & $4.6(2.5,6.8)$ & $-0.2(-2.6,2.3)$ & 0.796 \\
$\mathrm{CAT}$ & $18.00(15.00,32.00)$ & $19.00(11.00,26.00)$ & $-3.00(-6.00,-1.00)$ & 0.000 \\
FEVI & $0.90(0.74, I .46)$ & $1.07(0.91,0.59)$ & $0.12(-0.04,0.25)$ & 0.000 \\
FEVI/FVC & $48.9 \pm 11.5$ & $52.1 \pm 14.3$ & $0.52(-2.2,5.0)$ & 0.048 \\
FEVI\% & $39.6(30.1,54.1)$ & $49.7 \pm 18.2$ & $4.3(-2.7,9.8)$ & 0.003 \\
PEF & $2.9(2.0,3.9)$ & $3.7(2.6,4.8)$ & $0.35 \pm 1.43$ & 0.013 \\
FEF25 & $0.83(0.58,1.78)$ & $1.47(0.72,2.60)$ & $0.13(-0.10-0.65)$ & 0.000 \\
FEF50 & $0.42(0.28,0.76)$ & $0.58(0.37,1.11)$ & $0.06(-0.05-0.26)$ & 0.006 \\
FEF75 & $0.19(0.15,0.29)$ & $0.24(0.16,0.34)$ & $0.03 \pm 0.16$ & 0.039 \\
\hline
\end{tabular}

Notes: Data are presented as mean \pm standard deviation or median (interquartile range); Kruskal-Wallis test for all other variables. 

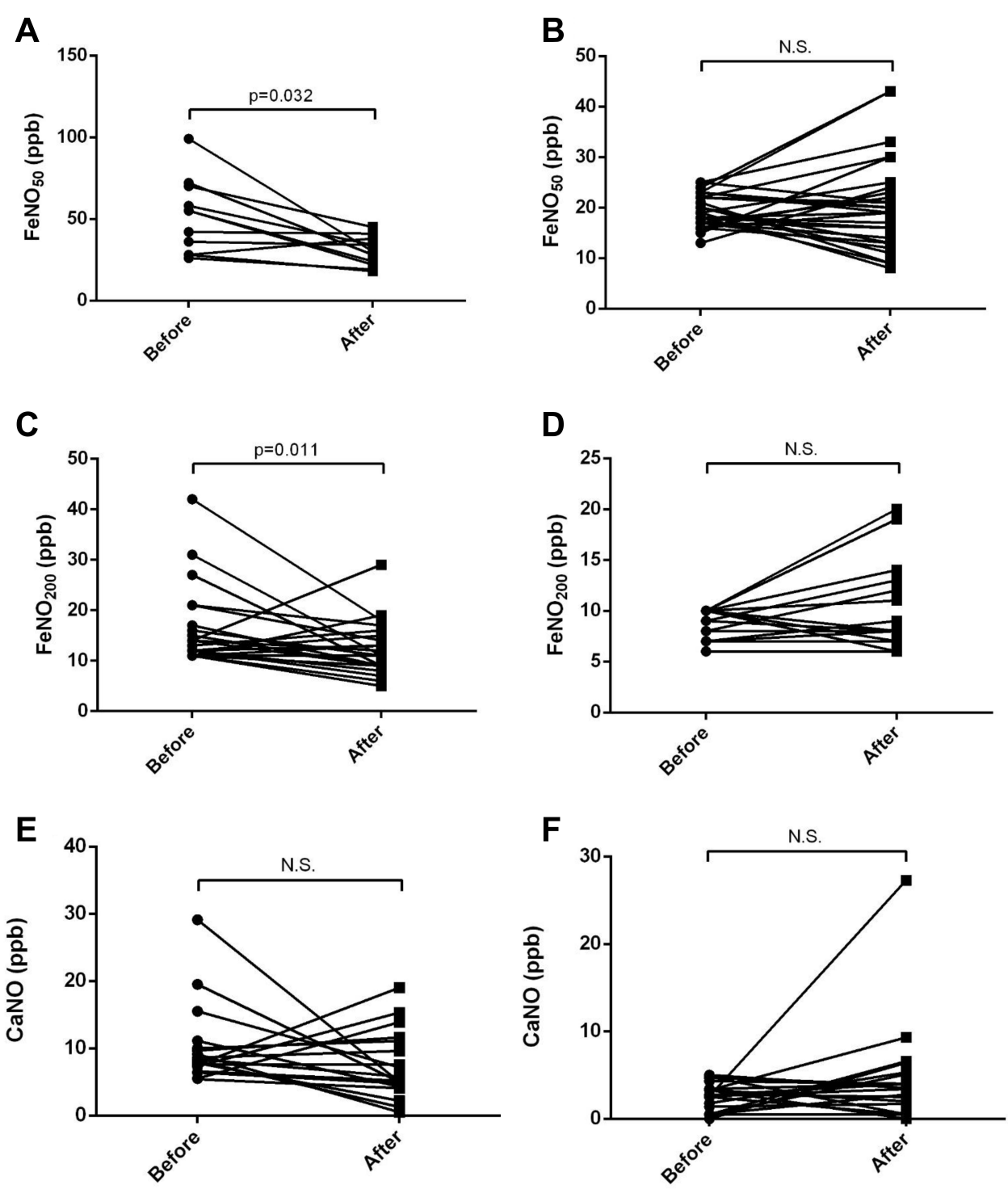

Figure 2 Changes in $\mathrm{FeNO}_{50}, \mathrm{FeNO}_{200}$ and $\mathrm{CaNO}$ in different groups. FeNO 50 in patients with initial $\mathrm{FeNO}_{50}>25 \mathrm{ppb}$ decreased after treatment $(\mathbf{A})$, FeNO $\mathrm{F}_{50}$ in patients with initial $\mathrm{FeNO}_{50} \leq 25 \mathrm{ppb}$ did not change after treatment (B), FeNO 200 in patients with initial $\mathrm{FeNO} \mathrm{NO}_{200}>10 \mathrm{ppb}$ decreased after treatment $(\mathrm{C})$, FeNO initial $\mathrm{FeNO}_{200} \leq 10 \mathrm{ppb}$ did not change after treatment (D), $\mathrm{CaNO}$ in patients with initial $\mathrm{CaNO}>5 \mathrm{ppb}$ did not change after treatment (E), $\mathrm{CaNO}$ in patients with initial $\mathrm{CaNO} \leq 5 \mathrm{ppb}$ did not change after treatment $(\mathbf{F})$

\section{Discussion}

Invasive sampling, such as lung biopsy or bronchoalveolar lavage (BAL), poses a risk to COPD patients, making it difficult to assess small airway and alveoli inflammation directly. Exhaled NO has been used as a noninvasive biomarker of airway inflammation since it was discovered. According to ERS guideline, $\mathrm{FENO}_{50}=\mathrm{CANO}+\mathrm{JawNO} /$ 50 at the flow rate of $50 \mathrm{~mL} / \mathrm{s}$ and $\mathrm{FENO}_{200}=\mathrm{CANO}$ $+\mathrm{JawNO} / 200$ at the flow rate of $200 \mathrm{~mL} / \mathrm{s}$. JawNO is the NO flux in the large airway, which reflects the NO production and inflammation in the large airway, and is not affected by the flow rate; similarly, CANO is the alveolar
NO concentration, which completely reflects the small airway inflammation and is not affected by the flow rate. Therefore, FENO $_{50}$ reflects more JawNO, that is, NO concentration in large airway, while $\mathrm{FeNO}_{200}$ reflects more $\mathrm{CANO}$, that is, NO concentration in small airway. We observed that $\mathrm{FeNO}_{200}$ elevated in both stable and acute exacerbated COPD patients. Further subgroup analysis implied that $\mathrm{FeNO}_{200}$ in AECOPD patients with greater than $10 \mathrm{ppb}$ decreased after systemic corticosteroid therapy. However, no similar changes in $\mathrm{CaNO}$ were found. As we know, this is the first report of assessing the role of $\mathrm{FeNO}_{200}$ in COPD and may have important clinical significance. 
Table 4 The Difference from Baseline in FeNO ${ }_{50}$, CAT and Pulmonary Function Test

\begin{tabular}{|l|l|l|l|}
\hline Variables & High FeNO $_{50}$ & Low FeNO & \\
\hline FeNO & P-value \\
CAT & $-24.00(-33.00,-2.00)$ & $-1.50(-4.75,6.75)$ & 0.018 \\
FEVI/FVC & $-6.00(-9.00,-4.00)$ & $-2.50(-4.00,0.50)$ & 0.031 \\
FEVI\% pred & $6.48(-0.74,8.68)$ & $2.44(-0.96,8.74)$ & 0.286 \\
FEVI & $2.70(-0.90,16.70)$ & $6.35(-0.88,9.78)$ & 0.340 \\
PEF & $0.09(-0.05,0.28)$ & $0.17(-0.05,0.26)$ & 0.370 \\
PEF25 & $0.20(-0.42,1.40)$ & $0.57(0.17,0.96)$ & 0.676 \\
PEF50 & $0.12(-0.15,0.72)$ & $0.18(0.00,0.48)$ & 0.906 \\
PEF75 & $0.12(-0.06,0.43)$ & $0.05(-0.02,0.23)$ & 0.427 \\
\hline
\end{tabular}

Notes: Data are presented as median (interquartile range); Kruskal-Wallis test for all other variables.

We discovered that $\mathrm{FeNO}_{200}$ in COPD and AECOPD patients were higher than those in the healthy control group, reflecting the peripheral airway inflammation in COPD patients. Also, our research showed that $\mathrm{FeNO}_{200}$ was correlated with CRP in stable COPD patients, which was consistent with some findings in CaNO. ${ }^{15,16}$

Table 5 The Difference from Baseline in $\mathrm{FeNO}_{200}$, CAT and Pulmonary Function Test

\begin{tabular}{|c|c|c|c|}
\hline Variables & High FeNO & Low FeNO 200 & P-value \\
\hline $\mathrm{FeNO}_{200}$ & $-4.00(-6.00,1.00)$ & $0.50(-0.75,4.00)$ & 0.017 \\
\hline CAT & $-4.00(-6.00,-3.00)$ & $-1.00(-3.75,0.50)$ & 0.031 \\
\hline FEVI/FVC & $2.62(-1.99,7.83)$ & $3.54(-0.17,13.76)$ & 0.542 \\
\hline FEVI\% pred & $3.50(-2.30,11.40)$ & $5.90(1.10,9.43)$ & 0.803 \\
\hline FEVI & $0.09(-0.04,0.24)$ & $0.19(-0.05,0.3 \mathrm{I})$ & 0.921 \\
\hline PEF & $0.72(-0.05,1.09)$ & $0.34(0.07,0.73)$ & 0.176 \\
\hline PEF25 & $0.13(-0.10,0.50)$ & $0.32(0.09,0.7 I)$ & 0.611 \\
\hline PEF50 & $0.05(-0.03,0.25)$ & $0.13(-0.02,0.28)$ & 0.863 \\
\hline PEF75 & $0.02(-0.01,0.13)$ & $0.04(0.00,0.10)$ & 0.922 \\
\hline
\end{tabular}

Notes: Data are presented as median (interquartile range); Kruskal-Wallis test for all other variables.

Table 6 The Difference from Baseline in CaNO, CAT and Pulmonary Function Test

\begin{tabular}{|l|l|l|l|}
\hline Variables & High CaNO & Low CaNO & P-value \\
\hline CaNO & $-1.50(-7.18,1.30)$ & $0.30(-1.30,4.05)$ & 0.107 \\
CAT & $-3.50(-5.00,-5.00)$ & $-3.00(-6.00,-1.00)$ & 0.951 \\
FEVI/FVC & $0.67(-1.81,4.47)$ & $6.48(0.22,14.42)$ & 0.135 \\
FEVI\% pred & $3.50(-1.35,9.25)$ & $6.30(0.00,16.40)$ & 0.407 \\
FEVI & $0.17(-0.07,0.27)$ & $0.09(-0.04,0.25)$ & 0.621 \\
PEF & $0.67(0.11,1.02)$ & $0.34(-0.42,0.34)$ & 0.873 \\
PEF25 & $0.13(-0.13,0.40)$ & $0.20(-0.15,0.20)$ & 0.135 \\
PEF50 & $0.04(-0.06,0.09)$ & $0.25(-0.35,0.25)$ & 0.010 \\
PEF75 & $-0.01(-0.01,0.08)$ & $0.04(-0.05,0.04)$ & 0.232 \\
\hline
\end{tabular}

Notes: Data are presented as median (interquartile range); Kruskal-Wallis test for all other variables.
Nevertheless, the same changes of $\mathrm{CaNO}$ were not found in this study. Our results are in line with a few studies, suggesting that $\mathrm{CaNO}$ did not differentiate healthy controls from COPD patients. ${ }^{18,27}$ However, several studies have found that the CaNO of COPD and AECOPD patients were higher than those of healthy controls. ${ }^{15,16}$ The inconsistency may be due to the use of different types of NO analyzers in these studies. CaNO varies with different flow rates, velocities, and various calculation models. Low, medium and high exhalation flow rates are needed for CaNO calculation, but this method is challenging to apply in COPD patients. ${ }^{11}$ Our pre-test showed that nitric oxide measurement only had a $70 \%$ success rate at $300 \mathrm{~mL} / \mathrm{s}$ expiratory flow rate. Thus, $\mathrm{FeNO}_{200}$ can reflect peripheral airway inflammation more directly and accurately. Compared with the complex operation and calculation of $\mathrm{CaNO}, \mathrm{FeNO}_{200}$ is an effective and simple method to evaluate small airway inflammation, especially in AECOPD patients. A larger sample size is needed for further research.

The peripheral airways $\mathrm{NO}$ measured by $\mathrm{FeNO}_{200}$ and the simplified $\mathrm{CaNO}$ were not elevated as we expected in AECOPD compared with the stable condition. Zsófia Lázár also reported the same results in CaNO. ${ }^{16}$ The airway production of $\mathrm{NO}$ would change along with the expression of endothelial, neuronal, and inducible isoforms of NO synthase (eNOS, nNOS, and iNOS) in the peripheral lung tissue of COPD patients. iNOS is believed to play a critical role in the inflammatory response. iNOS is increased by inflammatory mediators and can generate tremendous amounts of $\mathrm{NO}^{28}$ On the one hand, the activity of iNOS in AECOPD patients is enhanced by airway inflammation. ${ }^{29}$ On the other hand, hypoxia can induce damage to pulmonary capillaries endothelial cells and decrease eNOS activity. ${ }^{30}$ The NO concentration produced 

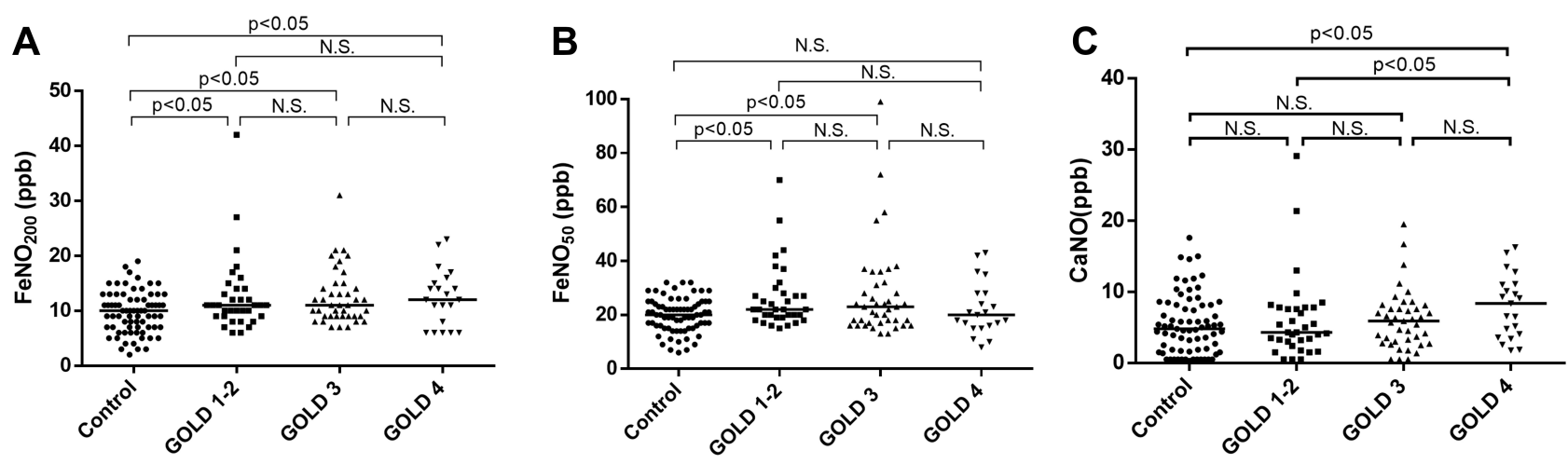

Figure $3 \mathrm{FeNO}_{50}, \mathrm{FeNO}_{200}$ and $\mathrm{CaNO}$ in healthy controls and COPD patients of different severity according to the classification of the Global Initiative for Chronic Obstructive Lung Disease (GOLD). FeNO 50 was not correlated with different GOLD stages (A). FeNO ${ }_{200}$ was not correlated with GOLD stages (B). CaNO was elevated at stage of GOLD4 (C).

by eNOS decreased when it diffused from alveolar capillaries to alveoli. Therefore, influenced by multiple factors, the level of NO did not change significantly in AECOPD patients. Further research is needed to understand the mechanism better.

Our findings showed that $\mathrm{FeNO}_{50}$ of AECOPD and stable COPD patients were higher than that of healthy controls, which agreed with previous studies. Zhiyu Lu reported that only a mild elevation of $\mathrm{FeNO}_{50}$ levels patients with stable COPD. ${ }^{31}$ However, no significant difference was found in $\mathrm{FeNO}_{50}$ between stable and exacerbated COPD patients. The reason may be consistent with $\mathrm{FeNO}_{200}$ as described above, and large airway NO could be suppressed by $\mathrm{ICS} .{ }^{31}$ Besides, the bacterial infection is an important cause of exacerbation of COPD. There was evidence showed that bacterial infection decreased $\mathrm{FeNO}_{50}$ levels. ${ }^{32}$ NO levels at lower expiratory flow rates mainly indicate the bronchial inflammation; therefore, $\mathrm{FeNO}_{50}$ cannot exactly reflect peripheral airway inflammation in COPD patients.

For AECOPD patients, there was no significant difference between $\mathrm{FeNO}_{200}$ and $\mathrm{CaNO}$ after systemic corticosteroid treatment. This result may be attributed to the low initial exhaled $\mathrm{NO}$ values in some patients, and these patients had an inadequate response to corticosteroid treatment. By classifying patients based on the cut-off point of $\mathrm{FeNO}_{50}>$ 25 , We identified that $31 \%$ of patients with higher $\mathrm{FeNO}_{50}$ levels had a significant $\mathrm{FeNO}_{50}$ decrease and improved CAT after corticosteroid treatment, suggesting an excellent response to corticosteroid. This finding agreed with ATS's guideline in 2011 that $\mathrm{FeNO}_{50}$ greater than 25ppb indicates eosinophilic inflammation and high $\mathrm{FeNO}_{50}$ in COPD patients predict a good corticosteroid response. ${ }^{18,33}$
Although there are no guidelines for FeNO200 and $\mathrm{CaNO}$, based on existing clinical studies, the FeNO200 and CaNO values of healthy people are less than $10 \mathrm{ppb}$ and 5 ppb, respectively. ${ }^{18,20,35-40}$ Our research showed a significant decrease in CAT and $\mathrm{FeNO}_{200}$ in patients with $\mathrm{FeNO}_{200}$ greater than $10 \mathrm{ppb}$ after corticosteroid therapy. Patients with FeNO200 below $10 \mathrm{ppb}$ did not change after treatment, whereas CaNO did not change after 1 week's corticosteroid treatment neither in the high $\mathrm{CaNO}$ value group nor in the low CaNO value group, which is similar to the previous study. ${ }^{16}$ The results implied that AECOPD patients with FeNO200 > 10 ppb would benefit from corticosteroid.

GOLD recommended that COPD patients with circulating eosinophils $>100$ cells $/ \mu \mathrm{L}$ can benefit from corticosteroid application. For patients with eosinophils $<100$ cells $/ \mu \mathrm{L}$, corticosteroid treatment is restrained due to poor response and the increased risk of pneumonia. ${ }^{41}$ In our study, $64 \%$ of patients had eosinophil counts greater than 100 cells $/ \mu \mathrm{L}$, similar to previous results. ${ }^{42}$ There were 59\% AECOPD patients with FeNO200 $>10$ ppb. However, only $31 \%$ of patients with AECOPD had FeNO50 greater than $25 \mathrm{ppb}$. Therefore, $\mathrm{FeNO}_{50}$ cannot truly reflect COPD's inflammatory state, and only measuring FeNO50 may miss some patients who would benefit from corticosteroid application. Compared with FeNO50, FeNO200 may be a better indicator of corticosteroid therapy in COPD patients.

\section{Conclusion}

This study proved that $\mathrm{FeNO}_{200}$ was a simpler and more patient-friendly method to directly measure the NO levels of peripheral airway/alveoli in COPD patients. In AECOPD patients with $\mathrm{FeNO} 200>10 \mathrm{ppb}$ presented a better response 
to corticosteroid treatment. Moreover, it is consistent with the guidance of peripheral blood eosinophils counts. Therefore, FeNO200 can be a type 2 inflammation biomarker and a useful tool for corticosteroid treatment in COPD.

\section{Ethics Approval and Consent to Participate}

The study was approved by the ethical review board of Wuxi People's Hospital Affiliated to Nanjing Medical University. The ethics approval number was KS000024.

\section{Acknowledgments}

The study was supported by the project of the project of Jiangsu commission of Health [BJ15009 and BJ17009] and the Natural Science Foundation of Wuxi [JZYX01].

\section{Disclosure}

The authors declare that they have no conflicts of interest in this work.

\section{References}

1. Negewo NA, Gibson PG, McDonald VM. COPD and its comorbidities: impact, measurement and mechanisms. Respirology. 2015;20:1160-1171. doi:10.1111/resp.12642

2. Barnes PJ. Inflammatory mechanisms in patients with chronic obstructive pulmonary disease. J Allergy Clin Immunol. 2016;138 (1):16-27. doi:10.1016/j.jaci.2016.05.011

3. Christenson SA, Steiling K, van den Berge M, et al. Asthma-COPD overlap. Clinical relevance of genomic signatures of type 2 inflammation in chronic obstructive pulmonary disease. Am J Respir Crit Care Med. 2015;191(7):758-766. doi:10.1164/rccm.201408-1458OC

4. Oishi K, Matsunaga K, Shirai T, et al. Role of type2 inflammatory biomarkers in chronic obstructive pulmonary disease. $J$ Clin Med. 2020;9(8):2670. doi:10.3390/jcm9082670

5. Beg MF, Alzoghaibi MA, Abba AA, et al. Exhaled nitric oxide in stable chronic obstructive pulmonary disease. Ann Thorac Med. 2009;4:65-70. doi:10.4103/1817-1737.44649

6. Bazeghi N, Gerds TA, Budtz-Jorgensen E, et al. Exhaled nitric oxide measure using multiple flows in clinically relevant subgroups of COPD. Respir Med. 2011;105:1338-1344. doi:10.1016/j. rmed.2011.03.015

7. Chou KT, Su KC, Huang SF, et al. Exhaled nitric oxide predicts eosinophilic airway inflammation in COPD. Lung. 2014;192:499-504. doi:10.1007/s00408-014-9591-8

8. Malerba M, Radaeli A, Olivini A, et al. Exhaled nitric oxide as a biomarker in COPD and related comorbidities. Biomed Res Int 2014;2014:271918. doi:10.1155/2014/271918

9. Karampitsakos T, Gourgoulianis KI. Asthma-COPD overlap syndrome (ACOS): single disease entity or not? Could exhaled nitric oxide be a useful biomarker for the differentiation of ACOS, asthma and COPD? Med Hypotheses. 2016;91:20-23. doi:10.1016/j. mehy.2016.04.008

10. Alcazar-Navarrete B, Ruiz Rodriguez O, Conde Baena P, et al. Persistently elevated exhaled nitric oxide fraction is associated with increased risk of exacerbation in COPD. Eur Respir J. 2018;51:1701457. doi:10.1183/13993003.01457-2017
11. Horvath I, Barnes PJ, Loukides S, et al. A European respiratory society technical standard: exhaled biomarkers in lung disease. Eur Respir J. 2017;49:1600965. doi:10.1183/13993003.00965-2016

12. Hogman M, Holmkvist T, Wegener T, et al. Extended NO analysis applied to patients with COPD, allergic asthma and allergic rhinitis. Respir Med. 2002;96:24-30. doi:10.1053/rmed.2001.1204

13. Brindicci $\mathrm{C}$, Ito $\mathrm{K}$, Resta $\mathrm{O}$, et al. Exhaled nitric oxide from lung periphery is increased in COPD. Eur Respir J. 2005;26:52-59. doi:10.1183/09031936.04.00125304

14. Williamson PA, Clearie K, Menzies D, et al. Assessment of small-airways disease using alveolar nitric oxide and impulse oscillometry in asthma and COPD. Lung. 2011;189:121-129. doi:10.1007/ s00408-010-9275-y

15. Hirano T, Matsunaga K, Sugiura $\mathrm{H}$, et al. Relationship between alveolar nitric oxide concentration in exhaled air and small airway function in COPD. J Breath Res. 2013;7:046002. doi:10.1088/17527155/7/4/046002

16. Lazar Z, Kelemen A, Galffy G, et al. Central and peripheral airway nitric oxide in patients with stable and exacerbated chronic obstructive pulmonary disease. J Breath Res. 2018;12:036017. doi:10.1088/ 1752-7163/aac10a

17. Short PM, Williamson PA, Lipworth BJ. Effects of extra-fine inhaled and oral corticosteroids on alveolar nitric oxide in COPD. Lung. 2012;190:395-401. doi:10.1007/s00408-012-9378-8

18. Gelb AF, Flynn Taylor C, Krishnan A, et al. Central and peripheral airway sites of nitric oxide gas exchange in COPD. Chest. 2010;137:575-584. doi:10.1378/chest.09-1522

19. Paredi P, Kharitonov SA, Meah S, et al. A novel approach to partition central and peripheral airway nitric oxide. Chest. 2014;145:113-119. doi:10.1378/chest.13-0843

20. Delclaux C, Mahut B, Zerah-Lancner F, et al. Increased nitric oxide output from alveolar origin during liver cirrhosis versus bronchial source during asthma. Am $J$ Respir Crit Care Med. 2002;165:332-337. doi:10.1164/ajrccm.165.3.2107017

21. Gupta S, Zamel N, Faughnan ME. Alveolar exhaled nitric oxide is elevated in hereditary hemorrhagic telangiectasia. Lung. 2009;187:43-49. doi:10.1007/s00408-008-9125-3

22. Lam Shin Cheung J, Naimi M, Sykes J, et al. A role for alveolar exhaled nitric oxide measurement in the diagnosis of hepatopulmonary syndrome. J Clin Gastroenterol. 2020;54:278-283. doi:10.1097/ MCG.0000000000001246

23. American Thoracic Society; European Respiratory Society. ATS/ERS recommendations for standardized procedures for the online and offline measurement of exhaled lower respiratory nitric oxide and nasal nitric oxide, 2005. Am J Respir Crit Care Med. 2005;171 (8):912-930. doi:10.1164/rccm.200406-710ST

24. Tsoukias NM, George SC. A two-compartment model of pulmonary nitric oxide exchange dynamics. J Appl Physiol. 1998;85:653-666. doi:10.1152/jappl.1998.85.2.653

25. Hogman M, Merilainen P. Extended NO analysis in asthma. $J$ Breath Res. 2007;1:024001. doi:10.1088/1752-7155/1/2/024001

26. Hogman M. Extended NO analysis in health and disease. $J$ Breath Res. 2012;6:047103. doi:10.1088/1752-7155/6/4/047103

27. Lehouck A, Carremans C, De Bent K, et al. Alveolar and bronchial exhaled nitric oxide in chr onic obstructive pulmonary disease. Respir Med. 2010;104:1020-1026. doi:10.1016/j.rmed.2010.01.001

28. Sugiura $H$, Ichinose M. Nitrative stress in inflammatory lung diseases. Nitric Oxide. 2011;25:138-144. doi:10.1016/j. niox.2011.03.079

29. Pavord ID, Jones PW, Burgel PR, et al. Exacerbations of COPD. Int J Chron Obstruct Pulmon Dis. 2016;11:21-30. doi:10.2147/ COPD.S85978

30. Zong F, Zuo XR, Wang Q, et al. Iptakalim rescues human pulmonary artery endothelial cells from hypoxia-induced nitric oxide system dysfunction. Exp Ther Med. 2012;3:535-539. doi:10.3892/ etm.2011.414 
31. Papi A, Bellettato CM, Braccioni F, et al. Infections and airway inflammation in chronic obstructive pulmonary disease severe exacerbations. Am J Respir Crit Care Med. 2006;173:1114-1121. doi:10.1164/rccm.200506-8590C

32. Lu Z, Huang W, Wang L, et al. Exhaled nitric oxide in patients with chronic obstructive pulmonary disease: a systematic review and meta-analysis. Int $J$ Chron Obstruct Pulmon Dis. 2018;13:2695-2705. doi:10.2147/COPD.S165780

33. Dweik RA, Boggs PB, Erzurum SC, et al. An official ATS clinical practice guideline: interpretation of exhaled nitric oxide levels (FENO) for clinical applications. Am J Respir Crit Care Med. 2011;184:602-615. doi:10.1164/rccm.9120-11ST

34. Yamaji Y, Oishi K, Hamada K, et al. Detection of type 2 biomarkers for response in COPD. J Breath Res. 2020;14:026007. doi:10.1088/ $1752-7163 / \mathrm{ab} 71 \mathrm{a} 4$

35. Hogman M, Ludviksdottir D, Anderson SD, et al. Inhaled mannitol shifts exhaled nitric oxide in opposite directions in asthmatics and healthy subjects. Respir Physiol. 2001;124:141-150. doi:10.1016/ S0034-5687(00)00195-X

36. Lehtimaki L, Kankaanranta H, Saarelainen S, et al. Extended exhaled NO measurement differentiates between alveolar and bronchial inflammation. Am J Respir Crit Care Med. 2001;163:1557-1561. doi:10.1164/ajrccm.163.7.2010171
37. Lehtimaki L, Kankaanranta H, Saarelainen S, et al. Increased alveolar nitric oxide concentration in asthmatic patients with nocturnal symptoms. Eur Respir J. 2002;20:841-845. doi:10.1183/ 09031936.02 .00202002

38. Tiev KP, Cabane J, Aubourg F, et al. Severity of scleroderma lung disease is related to alveolar concentration of nitric oxide. Eur Respir J. 2007;30:26-30. doi:10.1183/09031936.00129806

39. Hua-Huy T, Tiev KP, Chereau C, et al. Increased alveolar concentration of nitric oxide is related to serum-induced lung fibroblast proliferation in patients with systemic sclerosis. $J$ Rheumatol. 2010;37:1680-1687. doi:10.3899/jrheum.090915

40. Wuttge DM, Bozovic G, Hesselstrand R, et al. Increased alveolar nitric oxide in early systemic sclerosis. Clin Exp Rheumatol. 2010;28:S5-9.

41. Singh D, Agusti A, Anzueto A, et al. Global strategy for the diagnosis, management, and prevention of chronic obstructive lung disease: the GOLD science committee report 2019. Eur Respir J. 2019;53:1900164. doi:10.1183/13993003.00164-2019

42. Martinez-Garcia MA, Faner R, Oscullo G, et al. Inhaled steroids, circulating eosinophils, chronic airway infection, and pneumonia risk in chronic obstructive pulmonary disease: a network analysis. $\mathrm{Am}$ J Respir Crit Care Med. 2020;201:1078-1085. doi:10.1164/ rccm.201908-1550OC
International Journal of General Medicine

\section{Publish your work in this journal}

The International Journal of General Medicine is an international, peer-reviewed open-access journal that focuses on general and internal medicine, pathogenesis, epidemiology, diagnosis, monitoring and treatment protocols. The journal is characterized by the rapid reporting of reviews, original research and clinical studies

\section{Dovepress}

across all disease areas. The manuscript management system is completely online and includes a very quick and fair peer-review system, which is all easy to use. Visit http://www.dovepress.com/ testimonials.php to read real quotes from published authors. 